\title{
Maxillary Alveolar Process
}

National Cancer Institute

\section{Source}

National Cancer Institute. Maxillary Alveolar Process. NCI Thesaurus. Code C160973.

The portion of the maxilla that contains the sockets of the teeth. 